8-17-1992

\title{
Dynamic Analysis of Space-Related Linear and Nonlinear Structures
}

\author{
Paul A. Bosela \\ Cleveland State University, p.bosela@csuohio.edu \\ F. J. Shaker \\ NASA Lewis Research Center \\ D. G. Ertis \\ University of Akron
}

Follow this and additional works at: https://engagedscholarship.csuohio.edu/encee_facpub

Part of the Structures and Materials Commons

How does access to this work benefit you? Let us know!

\section{Publisher's Statement}

NOTICE: this is the author's version of a work that was accepted for publication in Computers \& Structures. Changes resulting from the publishing process, such as peer review, editing, corrections, structural formatting, and other quality control mechanisms may not be reflected in this document. Changes may have been made to this work since it was submitted for publication. A definitive version was subsequently published in Computers \& Structures, 44, 5 , (08-17-1992); 10.1016/0045-7949(92)90335-W

\section{Original Citation}

Bosela P. A., Shaker F. J. and Fertis D. G. (1992) Dynamic Analysis of Space-Related Linear and Nonlinear Structures. Computers \& Structures, 44, 5, 1145-1148 DOI: 10.1016/0045-7949(92)90335-W

This Article is brought to you for free and open access by the Civil and Environmental Engineering at EngagedScholarship@CSU. It has been accepted for inclusion in Civil and Environmental Engineering Faculty Publications by an authorized administrator of EngagedScholarship@CSU. For more information, please contact library.es@csuohio.edu. 


\title{
TECHNICAL NOTE
}

\section{DYNAMIC ANALYSIS OF SPACE-RELATED LINEAR AND NON-LINEAR STRUCTURES}

\author{
P. A. Bosela, $\dagger$ F. J. Shaker $\ddagger$ and D. G. Fertis $\S$ \\ †Department of Engineering Technology, Cleveland State University, Cleveland, OH 44115, U.S.A. \\ †NASA Lewis Research Center, Structural Systems, Dynamics Branch, Cleveland, OH 44135, U.S.A. \\ $\S$ Department of Civil Engineering, University of Akron, Akron, $\mathrm{OH} 44325$, U.S.A.
}

\begin{abstract}
In order to be cost-effective, space structures must be extremely light-weight, and subsequently, very flexible structures. The power system for Space Station 'Freedom' is such a structure. Each array consists of a deployable truss mast and a split 'blanket' of photo-voltaic solar collectors. The solar arrays are deployed in orbit, and the blanket is stretched into position as the mast is extended. Geometric stiffness due to the preload make this an interesting non-linear problem.

The space station will be subjected to various dynamic loads, during shuttle docking, solar tracking, attitude adjustment, etc. Accurate prediction of the natural frequencies and mode shapes of the space station components, including the solar arrays, is critical for determining the structural adequacy of the components, and for designing a dynamic controls system.

This paper chronicles the process used in developing and verifying the finite element dynamic model of the photo-voltaic arrays. Various problems were identified in the investigation, such as grounding effects due to geometric stiffness, large displacement effects, and pseudo-stiffness (grounding) due to lack of required rigid body modes. Various analysis techniques, such as development of rigorous solutions using continuum mechanics, finite element solution sequence altering, equivalent systems using a curvature basis, Craig-Bampton superelement approach, and modal ordering schemes were utilized. This paper emphasizes the grounding problems associated with the geometric stiffness.
\end{abstract}

$L$

\section{NOTATION}

factor defined by eqn (13)

arbitrary constants in eqn (10)

differential operator with respect to position

differential operator with respect to time

modulus of elasticity

axial strain

input force vector at the beginning of a step applied transverse force

factor defined by eqn (14)

moment of inertia

stiffness matrix

elastic stiffness matrix

geometric stiffness matrix

length

moment

change in moment

mass per unit length

axial force

pseudo-force necessary for equilibrium

force vector, output force vector at the end of a step

kinetic energy

displacements at the node points

longitudinal displacement

strain energy due to axial load

strain energy due to bending

transverse displacement

shear

change in shear

potential of the external loads

change in volume

axis defined by Fig. 1

axis defined by Fig. 1
$1 / 2$ the angle of rotation

factor defined by eqn (11)

factor defined by eqn (12)

angle of rotation

stress

\section{INTRODUCTION}

NASA's Space Station 'Freedom' consists of various modules supported by a space truss. Power for the space station will be provided by a deployable system of split blanket photo-voltaic arrays, which will have two degree of freedom rotational capabilities in order to track the sun during its orbit. The arrays are designed to be operated in a zero-gravity environment.

NASA Lewis Research Center, along with its contractors, have the responsibility for developing a verified finite element dynamics model of the solar arrays, which could be combined with the other space station substructures for both structural and dynamic control studies. The development of the model necessitated the use of unique procedures, and rigorous analytical checks.

The procedure included the following:

1. Development of an idealized model of the solar arrays, and derivation of a unique solution for the response frequencies for the idealized array cantilevered from the space truss, using equations developed from continuum mechanics [1].

2. Comparison of the frequencies from the MSC/NASTRAN finite element dynamic model of the idealized array with the rigorous solution from continuum mechanics [2].

3. Refinement of the finite element mesh.

4. Rigid body mode checks of the finite element models. 
5. Various parameter studies involving the amount of tension in the blanket, rigidity of the blanket tip beam, type of elements used, etc.

6. Craig-Bampton approach for appending rigid body modes to substructures (superelements) [3].

7. Modal ordering schemes for identifying 'important' modes.

8. Study of grounding effects due to lack of rigid body mode capabilities [4].

A detailed summary of the project was presented in [5]. It should be noted that this study is ongoing at the present time. This paper will be restricted to the grounding problems associated with the geometric stiffness due to blanket preload.

\section{GROUNDING}

The space station solar arrays were modeled utilizing MSC NASTRAN. As a routine check. the stiffness matrices generated by the model were multiplied by a matrix of rigid body modes. and large pseudo-forces were developed (grounding). The cause of this 'grounding' phenomenon was examined.

Firite element solves non-linear problems of the form

$$
\left.\left[\left\{K_{t}\right]+\left[K_{g}\right]\right\} u\right\}=\{R\}-\{F\},
$$

where $\left[K_{t}\right]$ is the elastic stiffness matrix, and $\left[K_{g}\right]$ is the geometric, or initial stress stiffness matrix.

$\left[K_{g}\right]$ is a function of the pre-load. Thus, it equals zero for a linear problem. $\left[K_{6}\right]$ possesses the required rigid body modes. However, $\left[K_{x}\right]$ lacks the capacity for rigid body rotation. Hence, an erroneus stiffening, or 'grounding', occurs when a pre-loaded beam deforms.

The traditional, or consistent geometric stiffness matrix, developed by Martın [6] and others. is

$$
K_{z}=P\left[\begin{array}{cccc}
6 / 5 L & 1 / 10 & -6 / 5 L & 1 / 10 \\
1 / 10 & 2 L / 15 & -1,10 & -L / 30 \\
-6 / 5 L & -l / 10 & 6 / 51 & -1 / 10 \\
1 / 10 & =L / 3 / & -1 / 10 & 2 L / 15
\end{array}\right]
$$

This matrix does not posses rigid body rotation capabilities. Various refinements to the geometric stiffness have been developed which contain higher order terms [6-8]. However, none of these possess all the rigid budy modes. Bosela [4] developed a modified $\left[K_{g}\right]$ with complete rigid body modes when used with an exact rigid body rotation matrix, but $\left[K_{e}\right]$ lost some of its rigid body capabilities.

Closer examination of the traditional formulation of $\left[K_{g}\right]$ indicated that there is a load imbalance in the representation, and that pseudo-forces occur to maintain equilibrium (Fig. 1).

In [9], Collar and Simpson indicate that the lack of rigid body rotation capabilities for $\left[K_{g}\right]$ is not a problem, because the energy representation is correct. It can be shown that it is correct to $\beta^{2}$ terms, but error does occur, as a function of $\beta^{4}$. For large rigid body rotation, as will occur with the solar arrays, this is significant.

It should be noted that as long as the pre-load $P$ is assumed to remain horizontal during rotation, work will be done by the force. Thus, true rigid body rotation cannot occur. In order for the strain energy to equal zero, the force $P$ must change its orientation as the beam rotates (i.e. a follower force).

\section{RIGOROUS SOLUTION OF PRE-LOADED BEAM}

Suppose we have an axially loaded beam in space subjected to a time varying transverse loading (Fig. 2). The kinetic energy is

$$
T=\int_{0}^{L} \frac{m\left(v^{\prime}\right)^{2}}{2} \mathrm{~d} x
$$

The strain energy due to bending is

$$
U_{B}=\int \frac{E I}{2}\left(v^{\prime \prime}\right)^{2} \mathrm{~d} x
$$

The strain energy due to axial load is

$$
U_{A}=\frac{1}{2} \int \sigma e_{a} \mathrm{~d} \text { Vol. }
$$

Letting $\mathrm{d}$ Vol $=\mathrm{d} A \mathrm{~d} x$ and applying non-linear elasticity yields

$$
U_{A}=\int \frac{E A}{2}\left[(\mathrm{~d} u / \mathrm{d} x)^{2}+\mathrm{d} u / \mathrm{d} x(\mathrm{~d} v / \mathrm{d} x)^{2}+1 / 4(\mathrm{~d} v / \mathrm{d} x)^{4}\right] \mathrm{d} x
$$

Neglecting axial displacement and higher order terms yields

$$
\left.U_{A}=\int_{0}^{L} \frac{P}{2}\left[\left(v^{\prime}\right)^{2}\right)\right] \mathrm{d} x
$$

The putential of the externc.l loads is

$$
\begin{aligned}
\mathrm{V}=-\int F(x, t) v \mathrm{~d} x+V \cdot v(0, t) \\
\quad+M_{0} v^{\prime}(0, t)-V_{L^{\prime}} v(L, t)-M_{L} v^{\prime}(L, t) .
\end{aligned}
$$

Applying Hamilton's principle, and performing the variation, yields

$$
\begin{aligned}
\int_{11}^{t 2} & {\left[\int_{0}^{L}\left[E I v^{\prime \prime} \delta\left(v^{\prime \prime}\right)+P v^{\prime} \delta\left(v^{\prime}\right)-m \dot{v} \delta(v)-F(x, t) \delta(v)\right] \mathrm{d} x\right.} \\
& +V_{0} \delta v(0, t)+M_{0} \delta v^{\prime}(0, t)-V_{L} \delta v(L, t) \\
& \left.-M_{L} \delta v^{\prime}(L, t)\right] \mathrm{d} t=0
\end{aligned}
$$

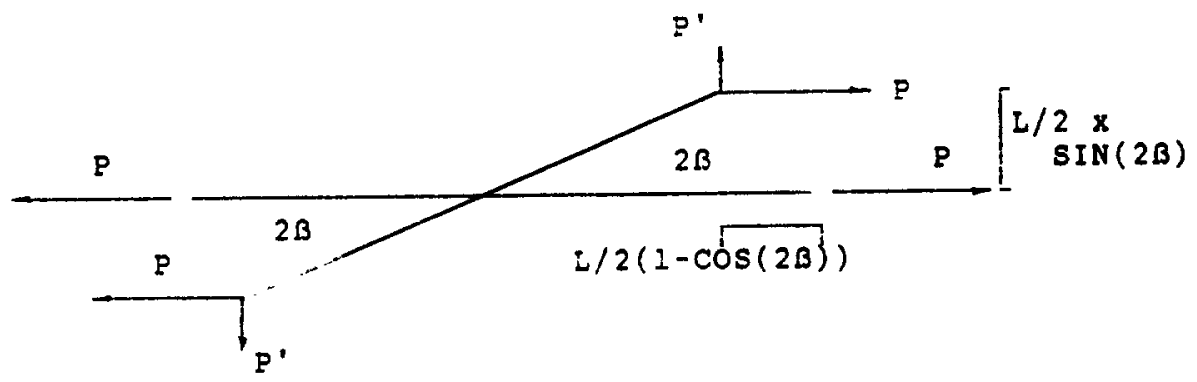

Fig. 1. $P^{\prime}$ represents pseudo-forces required for equilibrium. 

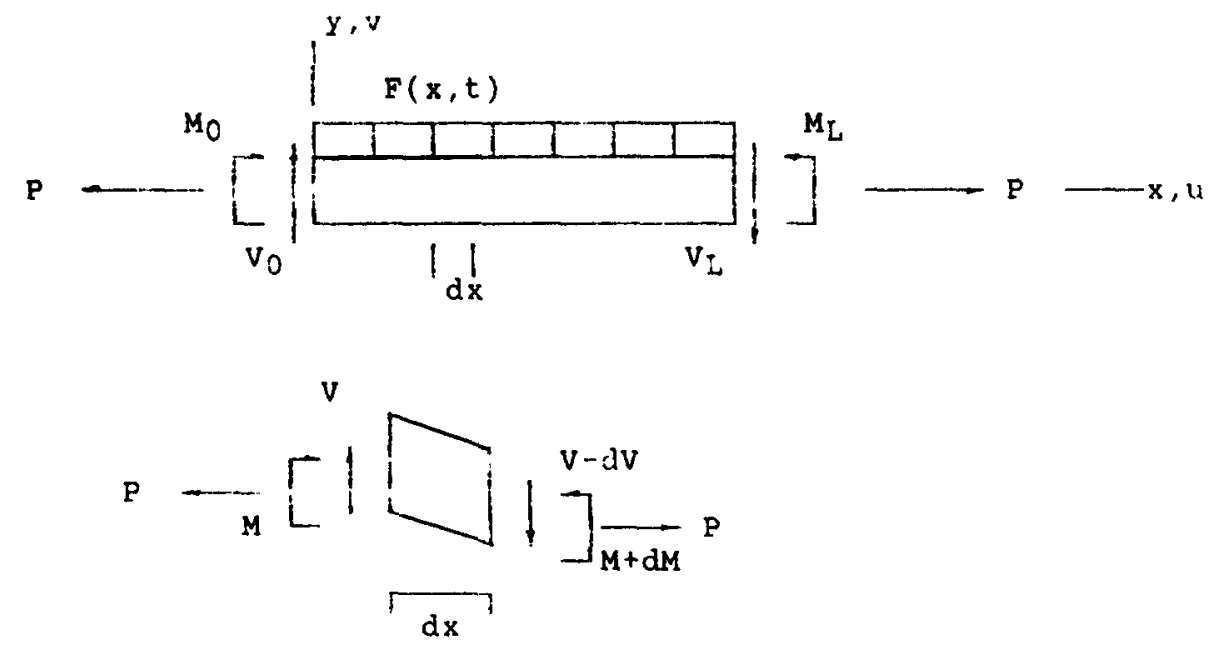

Fig. 2. Beam in tension and differential element.

Integrating by parts yields the differential equation

$\mathrm{d}^{2} / \mathrm{d} x^{2}\left(E I \mathrm{~d}^{2} v / \mathrm{d} x^{2}\right)-P \mathrm{~d}^{2} v / \mathrm{d} x^{2}+m \mathrm{~d}^{2} v / \mathrm{d} t^{2}=F(x, t)$,

which agrees with Clough [10], after a sign change required to express the axial force in tension instead of compression. This is also in agreement with Shaker [11].

For a beam in space, the moment and shear at the end points must equal zero. Thus, the boundary conditions are

$$
\begin{aligned}
E I v^{\prime \prime}(0, t) & =E I v^{\prime \prime}(L, t)=v^{\prime \prime \prime}(0, t)-\frac{P v^{\prime}}{E I}(0, t) \\
& =v^{\prime \prime \prime}(L, t)-\frac{P v^{\prime}}{E I}(L, t)=0 .
\end{aligned}
$$

Choose a solution of the form

$$
\begin{aligned}
v(x)=D_{1} \sin (\delta x)+ & D_{2} \cos (\delta x) \\
& +D_{3} \sinh (\epsilon x)+D_{4} \cosh (\epsilon x) .
\end{aligned}
$$

where

$$
\begin{gathered}
\delta=\left[\left(a^{4}+g^{4} / 4\right)^{1 / 2}-g^{2} / 2\right] \\
\epsilon=\left[\left(a^{4}+g^{4} / 4\right)^{1 / 2}+g^{2} / 2\right] \\
a^{4}=m w^{2} / E I \\
g^{2}=P / E I .
\end{gathered}
$$

Applying the boundary conditions at $x=0$, and after much mathematical manipulation, yields

$$
\begin{aligned}
v(x)=D_{3}\left[\frac{\delta}{\epsilon} \sin \delta x+\right. & \sinh \epsilon x] \\
& +D_{4}\left[\frac{\epsilon^{2}}{\delta^{2}} \cos \delta x+\cosh \epsilon x\right] .
\end{aligned}
$$

Applying the boundary conditions at $x=L$, and after more mathematical manipulations, yields

$$
D_{3}\left[\delta^{3} \cosh \epsilon L-\delta^{3} \cos \delta L\right]+D_{4}\left[\epsilon^{3} \sin \delta L+\delta^{3} \sinh \epsilon L\right]
$$

Expressing eqn (15) and eqn (16) into matrix form, setting the determinant equal to zero, and after more mathematical manipulations, the following characteristic equation is obtained

$$
\pm 2 a^{6}(\cosh \epsilon L \cos \delta L-1)+\left(\epsilon^{6}-\delta^{6}\right) \sinh \epsilon L \sin \delta L=0 .
$$

Using eqn (13), this can be expressed as

$$
\begin{aligned}
\pm w^{3}(m / E I)^{3 / 2}(\cosh \epsilon L & \cos \delta L-1) \\
& +\left(\epsilon^{6}-\delta^{6}\right) \sinh \epsilon L \sin \delta L=0 .
\end{aligned}
$$

By observation, when $w=0, a=0$, and $\delta=0$. Letting $\sin (0)=0$ yields

$$
w^{3}(m / E I)^{32}(\cosh \epsilon L \cos \delta L-1)=0 .
$$

The $w^{3}$ term indicates that there must be three zero roots of ' $w$ ', which suggests the three required rigid body modes.

\section{CONCLUSION}

Lack of complete rigid body mode capabilities is inherent in the physical representation of the pre-tensioned beam problem currently used to formulate the geometric stiffness matrix. This lack of complete rigid body mode capabilities invalidates the rigid body mode check for non-linear problems, and adversely impacts the use of traditional finite element techniques to predict dynamic response of preloaded structures unless the missing rigid body modes are somehow appended on to the structure, such as by the Craig-Bampton technique.

The rigorous solution of the axially-loaded beam with free/free boundary conditions developed in this paper may lend itself to the development of a new geometric stiffness matrix for a beam element with full rigid body capabilities.

Acknowledgement - This research was supported by research grant NAG 3-1008, with NASA Lewis Research Center.

\section{REFERENCES}

1. F. J. Shaker, Free-vibration characteristics of a large split-blanket solar array in a $1 \mathrm{G}$ field. NASA TN D-8376 (1976). 
2. K. S. Carney and F. J. Shaker, Free-vibration characteristics and correlation of a space station split-blanket solar array. NASA TM 101452 (1989).

3. R. R. Craig, Jr and M. C. C. Bampton, Coupling of substructures for dynamic analysis. $A I A A J n l 6$, 1313-1319 (1968).

4. P. A. Bosela, Limitations of current nonlinear finite element methods in dynamic analysis of solar arrays. MSC Users Conference, Los Angeles, CA, March (1989).

5. K. Carney, J. Chien, D. Ludwiczak, P. Bosela and F. Nekoogar, Photovoltaic Array Modeling and Normal Modes Analysis. NASA Lewis Research Center, Structural Dynamics Branch, Space Station Freedom WP04. Response Simulation and Structural Analysis, September (1989).
6. H. C. Martin and G. F. Carey, Introduction to Finite Element Analysis. McGraw-Hill (1973).

7. P. V. Marcal, The effect of initial displacements on problems of large deflection and stability. Division of Engineering, Brown University, Department of Defense Contract SD-86, ARPA E54 (1967).

8. D. M. Purdy and J. S. Przemieniecki, Influence of higher-order terms in the large deflection analysis of frameworks. Air Force Institute of Technology, Wright-Patterson Air Force Base, Ohio.

9. A. R. Collar and A. Simpson, Matrices and Engineering Dynamics. Halsted Press, New York (1987).

10. R. W. Clough and J. Penzien, Dynamics of Structures. McGraw-Hill (1975).

11. F. J. Shaker, Effect of axial load on mode shapes and frequencies of beams. NASA TN D-8109 (1975). 